\title{
A semi-distributed electric demand-side management system with PV generation for self-consumption enhancement
}

\author{
M. Castillo-Cagigal $^{\mathrm{a}, *}$, A. Gutiérrez ${ }^{\mathrm{a}}$, F. Monasterio-Huelin $^{\mathrm{a}}$, E. Caamaño-Martín ${ }^{\mathrm{b}}$, D. Masa ${ }^{\mathrm{b}}$, \\ J. Jiménez-Leube ${ }^{\mathrm{a}}$ \\ ${ }^{a}$ ETSI Telecomunicación, Universidad Politécnica de Madrid, Av. Complutense 30, 28040 Madrid, Spain \\ ${ }^{b}$ Instituto de Energía Solar, Universidad Politécnica de Madrid, Av. Complutense 30, 28040 Madrid, Spain
}

\section{A R T I C L E I N F O}

Keywords:

Demand-side management

Self-consumption

PV systems

Control system

Distributed energy

\begin{abstract}
A B S T R A C T
This paper presents the operation of an Electrical Demand-Side Management (EDSM) system in a real solar house. The use of EDSM is one of the most important action lines to improve the grid electrical efficiency. The combination between the EDSM and the PV generation performs a new control level in the local electric behavior and allows new energy possibilities. The solar house used as test-bed for the EDSM system owns a PV generator, a lead-acid battery storage system and a grid connection. The electrical appliances are controllable from an embedded computer. The EDSM is implemented by a control system which schedules the tasks commanded by the user. By using the control system, we define the house energy policy and improve the energy behavior with regard to a selected energy criterion, self-consumption. The EDSM system favors self-consumption with regard to a standard user behavior and reduces the energy load from the grid.
\end{abstract}

\section{Introduction}

The permanent increase of the electric demand is a general constant around the world. The availability, cost and sustainability of the energy resources have caused supply and energy instabilities in recent years. Moreover, environmental damages have shown the need for new energy models. Therefore, investments in new energy infrastructures and grid improvements must be achieved $[1,2]$.

Nowadays, this research is carried out mainly in the industrial sector because it holds the highest energy demand. However, the residential sector is not outside these problems, as this sector is the one which experiences the strongest increase on its electric demand [3]. Moreover, because of the number of users in the residential sector, its consumption is increasing in recent years, reaching the $28.8 \%$ of the total electricity consumption in the EU $[4,3]$. Therefore, the study of the electric demand in the residential sector is an important task for the electric grid controllers as already shown in $[5,6]$.

Recently, the European Commission requested a study to design strategies which guarantee a permanent electric supply to the

* Corresponding author. Tel.: +34 915495700; fax: +34913367278.

E-mail addresses: manuel.castillo@ies-def.upm.es (M. Castillo-Cagigal), aguti@etsit.upm.es (A. Gutiérrez), felix.monasteriohuelin@upm.es (F. MonasterioHuelin), estefan@ies-def.upm.es (E. Caamaño-Martin), dmasa@ies-def.upm.es (D. Masa), jleube@etsit.upm.es (J. Jiménez-Leube).. users [7]. This study concluded that new actions must be concentrated on the demand, where Electric Demand-Side Management (EDSM) techniques are excellent candidates [8]. A powerful attribute of the EDSM is when it is used together with Distributed Energy Resources (DERs). DER systems are small-scale power generation technologies used to provide an alternative or an enhancement of the traditional electric power system. This combination allows the use of local control systems, which may improve the efficiency and the energy forecast. However, the use of DERs must be handled with special care. The connection of several DER generators to the grid causes well studied problems such as generation randomness, reactive power increase and automatic shutdowns against voltage drops $[9,10]$. Hence, new improvements in the interaction of distributed generation and electricity networks must be carried out. Some of these developments have already been studied and tested in PV systems with remarkable success [11].

Furthermore, one of the main research fields which arises when combining EDSM and DERs is self-consumption. The use of selfconsumption systems are of particular interest for the development of a sustainable and responsible demand. When connected to the grid, self-consumption focuses on the usage of the own generated energy, while the energy provided by the grid remains as an optional generator or consumer. Therefore, self-consumption offers a stronger flexibility to the system, in which the power requested to the grid at peak times can be reduced by using the 
self-generated power. Because of these advantages, self-consumption starts to be present in many countries around the world as a technique to improve efficiency and stability [12].

In this paper, we propose a control architecture which focuses on the optimization of self-consumption over an EDSM system with PV generation as a DER. The EDSM system has been installed in a real house equipped with controllable appliances, a PV generation system, a battery system and a connection to the grid [13]. The system objective is to adapt the house behavior to a specific energy criterion.

The remainder of this paper is organized as follows. Section 2 describes the house and offers a brief overview about the PV system installed. In Section 3 the control architecture is described together with the controllable elements on it. Experimental results are presented in Section 4. Finally, Section 5 concludes the paper.

\section{The house}

The EDSM system has been developed and tested in a real solar house (see Fig. 1). The house integrates sustainable elements based on renewable energies, self-sufficiency energy methods, bioclimatic architecture and recycled construction materials [14].

As aforementioned, the DER system is based on a PV installation. Solar energy has a great potential in the residential sector and its presence is increasing since the last decade [15]. In our house, the PV installation consists of single-crystalline PV generators distributed in four south-oriented surfaces with different inclinations. The energy is collected in six arrays with a total nominal power of $7.2 \mathrm{~kW}_{\mathrm{p}}$.

Additionally, the house embodies a lead-acid battery energy storage system of $72 \mathrm{kWh}$. In a PV isolated installation the objective of the battery is to store the maximum amount of energy during the sun hours, so as to be used the rest of the day. However, in a grid-connected installation, as it is this house, batteries are used to improve the electrical behavior by controlling the maximum power consumption at different hours or ensuring the electric supply when a grid breakdown occurs [16-18]. In our application, the battery system stores the excess of PV energy and decreases the electricity demand to the grid.

The electrical system has been implemented based on an $A C$ topology (see Fig. 2). In this topology, the connection between the different parts is based on an $\mathrm{AC}$ bus. This connection allows the energy exchange between the different devices without an explicit hierarchy; therefore, it increases the system scalability. Notice that the battery stores only PV energy excess and it gives its stored energy solely to the loads. Therefore, there are not energy exchanges between the battery storage system and the grid.

Because of the different elements of the system, the electrical topology performs a variety of energy flows into the AC bus. These

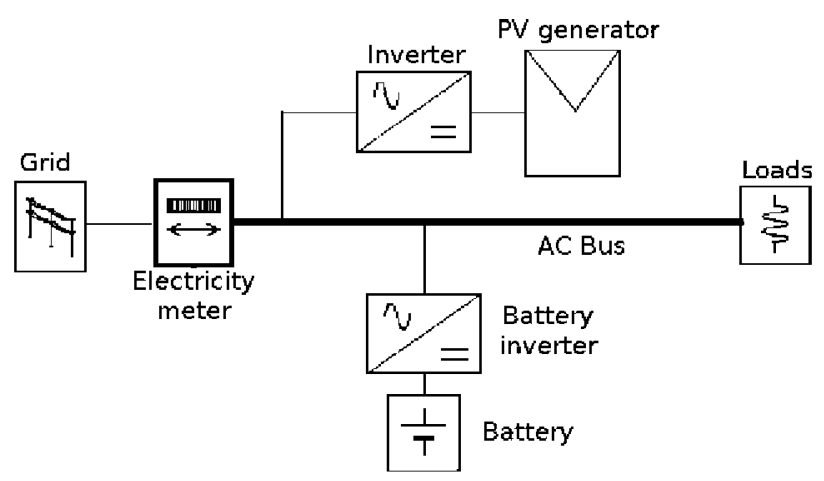

Fig. 2. Topology of the AC system installed in the solar house.

flows define the energy state of the house and are used by the control system (see Section 3). An schematic view of the energy flows is represented by the following equations:

$$
\begin{aligned}
& P_{\text {load }}<P_{P V}\left\{\begin{array}{l}
\text { If } E_{B s o c}<E_{B \max } \rightarrow P_{\text {bat }}=\rho_{i} \cdot\left(P_{\text {load }}-P_{P V}\right) \\
\text { If } E_{B s o c}=E_{B \max } \rightarrow P_{\text {grid }}=P_{\text {load }}-P_{P V}
\end{array}\right. \\
& P_{\text {load }}=P_{P V} \rightarrow P_{\text {bat }}=0, \quad P_{\text {grid }}=0 \\
& P_{\text {load }}>P_{P V}\left\{\begin{array}{l}
\text { If } E_{B s o c}>E_{\text {min }} \rightarrow \rho_{o} \cdot P_{\text {bat }}+P_{P V}=P_{\text {load }} \\
\text { If } E_{B s o c}=E_{B \min } \rightarrow P_{P V}+P_{\text {grid }}=P_{\text {load }}
\end{array}\right.
\end{aligned}
$$

where:

- $P_{\text {load }}$ is the power consumed by the loads. It is always positive.

- $P_{P V}$ is the power generated by the photovoltaic system. It is always positive.

- $P_{\text {grid }}$ is the power exchanged with the grid. It can be either positive, when we consume from the grid or negative when we supply energy to it.

- $P_{b a t}$ is the power exchanged with the battery storage system. It is positive when we get power from the battery storage system or negative when we charge it. Notice that this power represents the internal energy exchange because the battery performance coefficients are into equations.

- $E_{B s o c}$ is the state of charge of the battery storage system. It is always positive.

- $E_{B \max }$ is the maximum charge level of the battery storage system.

- $E_{B \min }$ is the minimum charge level of the battery storage system.

- $\rho_{i}$ is the input battery performance coefficient.

- $\rho_{o}$ is the output battery performance coefficient.

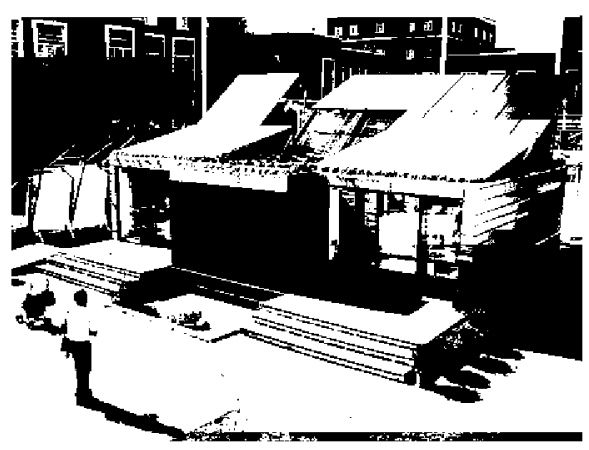

(a)

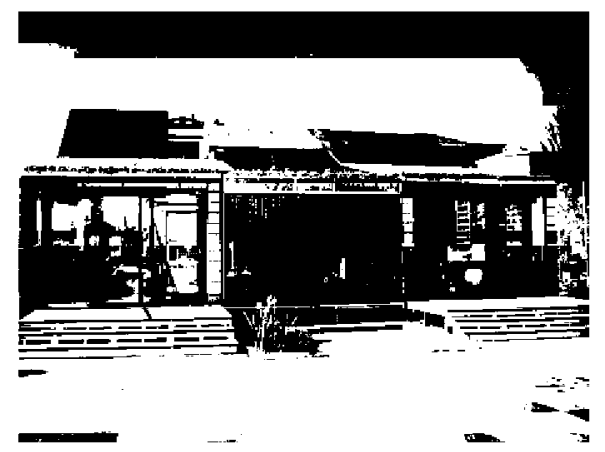

(b)

Fig. 1. (a) Birds eye view and (b) south frontage of the solar house. 


\section{Control system}

\subsection{The setup and the objectives}

The main objective of the EDSM system is to schedule different tasks commanded by the user throughout the day. The tasks at home can be classified into two different types: (i) deferrable and (ii) no-deferrable. Deferrable tasks can be moved in time; that is the ones which can be executed within certain time limits (e.g., the washing machine can be started form 10:00 to 15:00, but it must be finished before 16:00). On the other hand, no-deferrable tasks cannot be moved in time and must be executed at the time asked by the user (e.g., the TV must be switched on).

The EDSM system presented in this paper works with deferrable tasks. It tries to modified the time at which each task is executed to optimize an energy criterion. No-deferrable tasks are not taken into account by the EDSM system. However, they have been considered for sizing the PV system.

For the EDSM system implementation we have installed eight different controllable appliances in the house: Washing machine, dryer, dishwasher, hood, oven, refrigerator, freezer and air conditioning. The appliances are connected to a Power-Line bus governed by a residential gateway (see Fig. 3), this communication technology has been already used to perform distributed energy management [19]. The gateway owns a web server which provides an interface to start, stop and pause remotely each appliance. Moreover, the gateway is able to offer real time information about the actual status of each appliance.

To allow the EDSM system to create the planning, the user must provide a list with the appliances to execute the next $24 \mathrm{~h}$. He must provide the name of the appliance together with the program variables and the time limits. A summary of these variables is presented in Table 1 . Note that we assume that the user is involved in the EDSM system and he offers flexibility by giving time limits to the appliances which must be executed.

Before starting, the EDSM system must know the tasks the user wants to execute, the PV generation forecast and the actual battery state of charge. At that time, it starts planning the different tasks according to a specified energy criterion. The energy criterions can represent different energy or economic objectives. To reach an efficient EDSM, in this paper, the EDSM system has been programmed in order to favor self-consumption. Note the EDSM system does not reduce the energy consumption, but moves the tasks throughout the day favoring the use of our own generated energy. The experiments presented in Section 4 will show how the EDSM system is able to maximize the PV consumption at the detriment of the grid use.

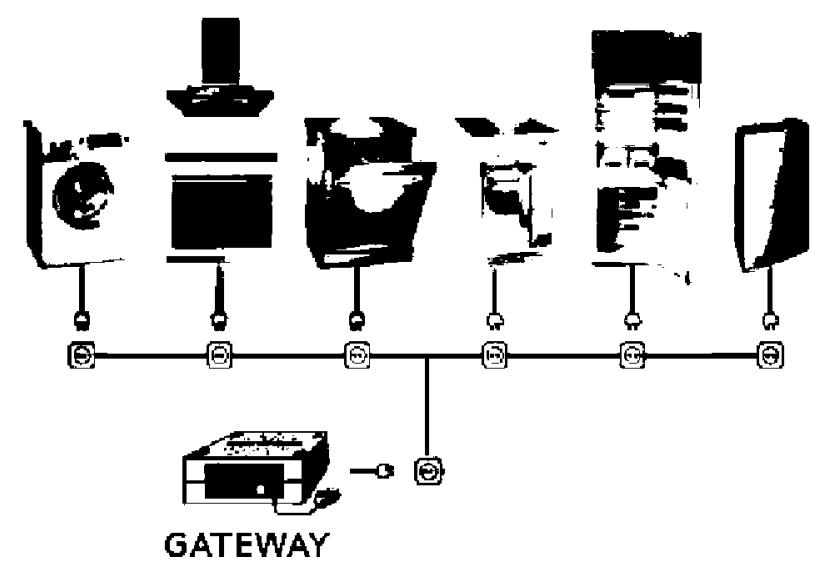

Fig. 3. Depiction of the Power-Line bus which governs the controllable appliances in the house.
Table 1

Appliances variables supplied by the user to the control system for its scheduling on the next $24 \mathrm{~h}$.

\begin{tabular}{lll}
\hline Appliance & Variable 1 & Variable 2 \\
\hline Washing machine & Temperature & Spin revolutions \\
Dryer & Spin revolutions & Not used \\
Dishwasher & Washing parameter & Not used \\
Oven & Temperature & Cooking time \\
Hood & Fan speed & Light intensity \\
Refrigerator & Temperature & Not used \\
Freezer & Temperature & Not used \\
Air conditioning & Temperature & Cooling time \\
\hline
\end{tabular}

\subsection{Architecture}

To implement the EDSM system, we have developed a modular architecture (see Fig. 4). The architecture is divided in two main blocks, one distributed and one centralized.

The distributed block is divided in sub-systems. Each sub-system is made up of the appliance, a communication module and a data base which holds information about the appliance. Each appliance receives information of its execution; that is, if it must be executed or not in the following $24 \mathrm{~h}$. In case it must be executed, it receives which is the program and the time limits in which it has to work. As a first step, each appliance places itself inside the time limits requested by the user. Then, it communicates with the others to obtain their orders and generates an egocentric scheduling. This egocentric scheduling means that each appliance will supply a planning which includes all the appliances requested by the user to be executed but favoring itself. Once the different plannings have been created, they are offered to the centralized block.

As an example, the user could have ordered the execution of three appliances as shown in Table 2 . An standard scheduling outcome is presented in Fig. 5.

The centralized block receives the different plannings and decides which one to execute in accordance with the specified energy criterion. As observed in Fig. 4, the centralized block is divided in two layers: (i) the coordination layer and (ii) the actuation layer. In addition to the plannings, the coordination layer receives energy information. This information includes the PV generation forecast, the battery state of charge and the grid state. Moreover, it obtains information about the appliances consumption and program duration stored in a data base (see Section 3.3). Furthermore, the coordination layer is aware of the house energy flows explained in Section 2 . By using these energy flows, the coordination layer forecasts the energy behavior of each planning proposed by the distributed block. Finally, the energy criterion is applied to decide which planning will be carried out.

Once a planning has been chosen, it is sent to the actuation layer. The actuation layer executes and monitors the planning selected. It is permanently monitoring the actual time and comparing it with the time at which each appliance must be executed. If both variables agree, it starts the appliance execution. Simultaneously, the actuation layer reads information from some electricity meters installed in the house which are measuring the energy flows. By comparing the forecasted energy balance and the measured one, the forecasted error and the real energy behavior can be observed.

\subsection{Data base}

As aforementioned, the EDSM system needs a data base which must be used to calculate the program duration of the appliances and their energy consumption. In an ideal system, this information should be provided by the appliances. However, given the actual development status of these smart appliances, this information is 


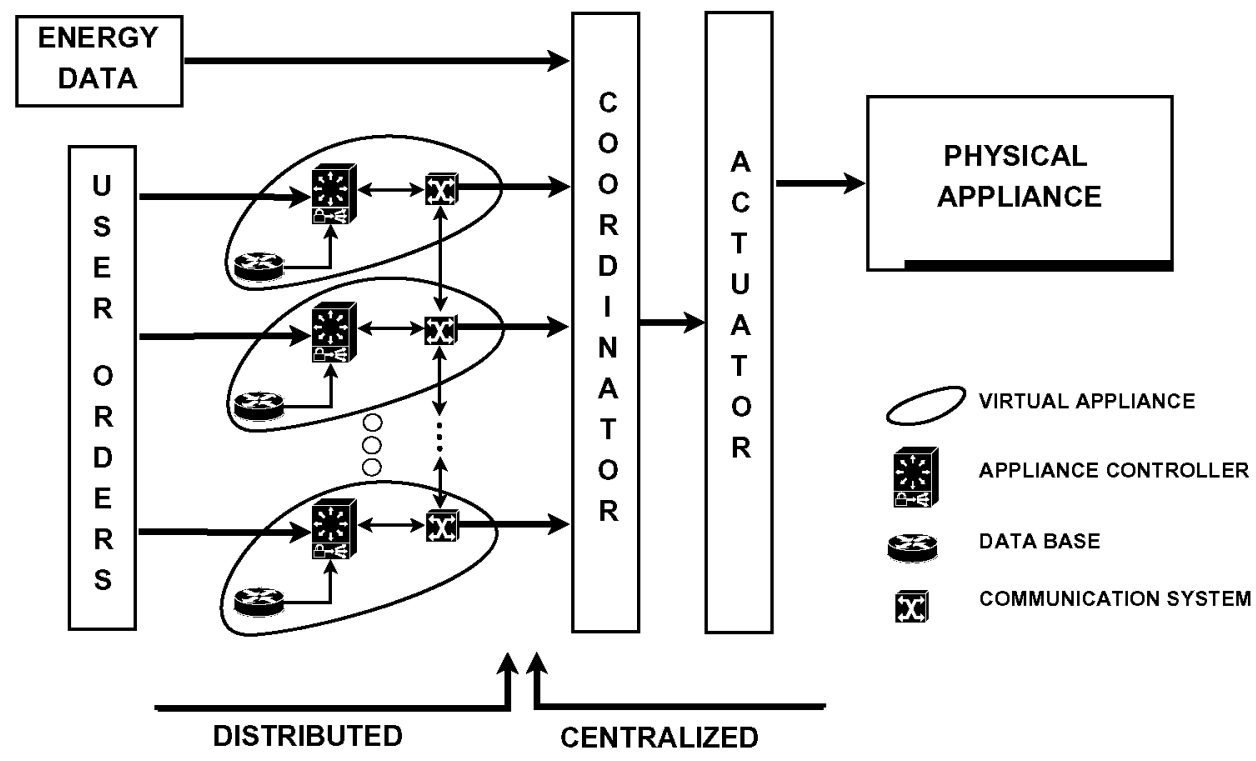

Fig. 4. Block diagram of the control architecture.

Table 2

Example of a standard execution ordered by the user.

\begin{tabular}{lllll}
\hline Appliance & Variable 1 & Variable 2 & Start time & End time \\
\hline Washing machine & $90^{\circ} \mathrm{C}$ & $1200 \mathrm{rpm}$ & $06: 00$ & $16: 00$ \\
Dryer & $1200 \mathrm{rpm}$ & Not used & $08: 00$ & $23: 00$ \\
Dishwasher & Quick wash & Not used & $04: 00$ & $16: 00$ \\
\hline
\end{tabular}

not accessible. To achieve this goal, we have built a data base associated to each appliance which embodies a table where the different programs are modeled in terms of energy and duration. This data base has been created after a statistical study of the appliances execution. For its creation, each appliance was plugged into a wattmeter. Each program was run 10 times and the energy and duration mean was used as the appliance behavior.

As an example, Fig. 6 shows the washing machine power consumption at two different temperatures $\left(40^{\circ} \mathrm{C}\right.$ and $\left.90^{\circ} \mathrm{C}\right)$ and a spin revolution of $1200 \mathrm{rpm}$. The principal difference observed is the energy consumption in the heating phase (beginning of the program). Note, it is important that this appliance behavior information can be offered to the users in order to improve their habits.

\section{Experiments}

\subsection{Evaluation method}

Because the control system behavior must be analyzed in terms of energy, we have developed two coefficients which evaluate the energy behavior for a given time period. In our experiments this period has been fixed to $24 \mathrm{~h}$.

Let us define the PV energy production of the house as:

$E_{P V}=E_{P V l}+E_{P V b}+E_{P V g}$

where $E_{P V}$ is the total amount of energy generated by the PV installation, $E_{P V l}$ is the PV energy used by the loads at the same time of production, $E_{P V b}$ is the PV energy given to the battery and $E_{P V g}$ is the PV energy given to the grid.

Let us define the internal battery energy relationship as:

$E_{\text {Ibat }}=E_{\text {Ebat }}+E_{B s o c}-E_{B s o c, 0}$

where $E_{\text {Ibat }}$ is the total amount of energy introduced on the battery, $E_{E b a t}$ is the total amount of extracted energy from the battery, $E_{B s o c}$ is the final battery state of charge at the evaluated time period and
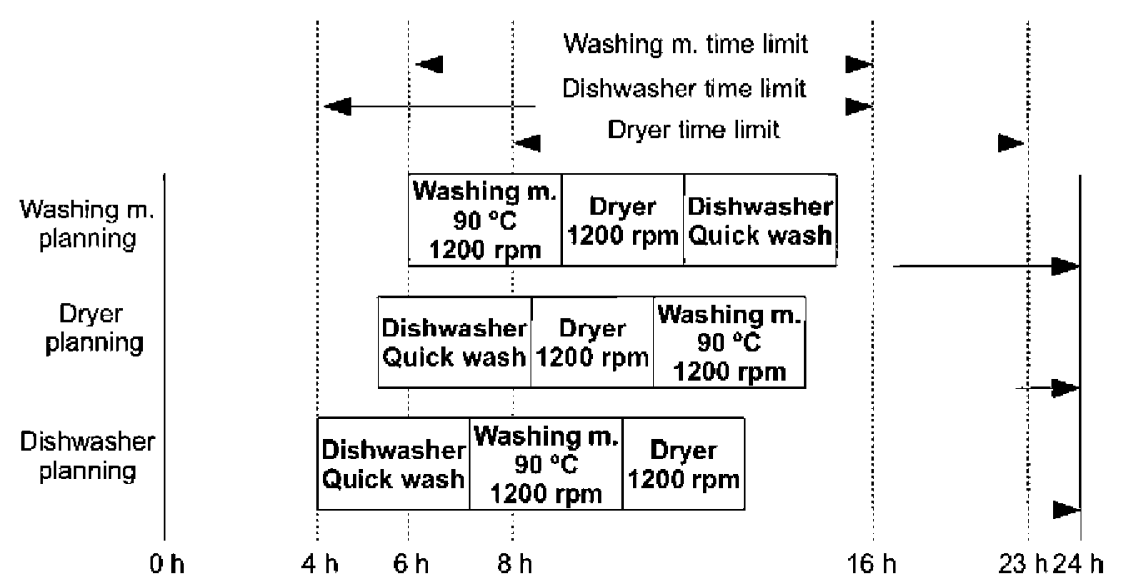

Fig. 5. Example of different plannings offered by the distributed sub-systems to the centralized block. 


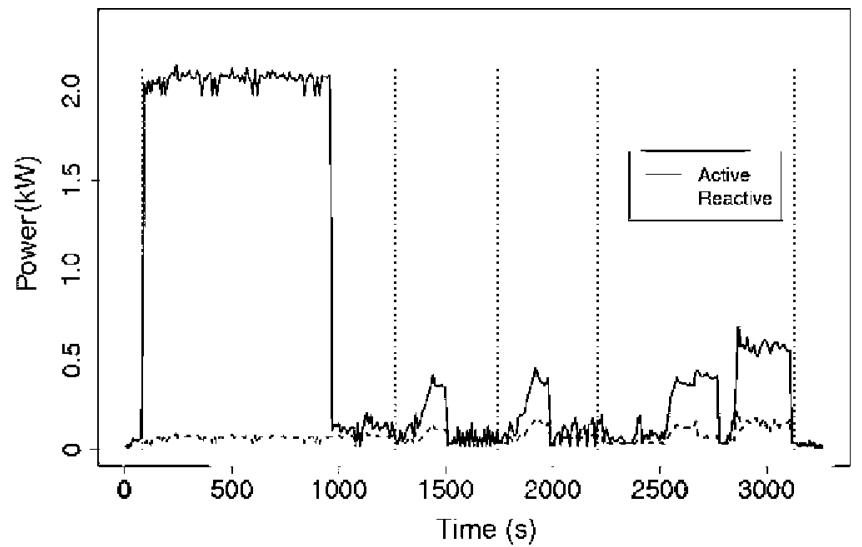

(a)

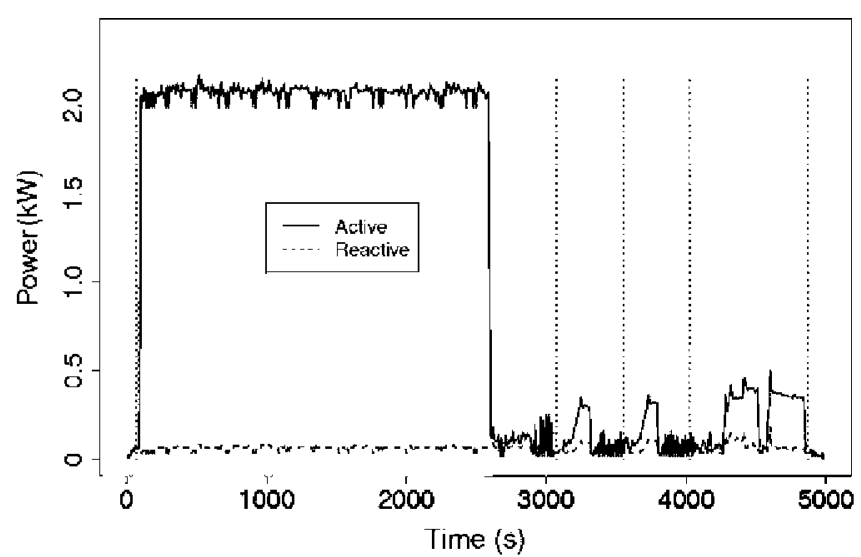

(b)

Fig. 6. Washing machine consumption at $1200 \mathrm{rpm}$ and (a) $40^{\circ}$ and (b) $90^{\circ}$.

$E_{B s o c, 0}$ is the initial battery state of charge at the evaluated time period.

Let us define the relationship between the energy generation and the energy storage as:

$E_{\text {lbat }}=\rho_{i} E_{P V b}$

where $\rho_{i}$ is the input battery performance coefficient with a value of 0.9 in our system. Notice that Eq. 6 implies that the battery is charged only by the PV system and not the grid.

Let us define $E_{\text {grid }}$ as the energy extracted from the grid and $E_{\text {load }}$ as the energy used by the house. Therefore, the energy used to supply the consumption is defined as:

$E_{\text {load }}=E_{P V}+E_{\text {grid }}+\rho_{0} E_{\text {Fbat }}$

where $\rho_{o}$ is the output battery performance coefficient with a value of 0.9 in our system.

Based on the previous definitions, let us define $\xi$ as the self-consumption coefficient:

$\xi=\frac{E_{P V}+\rho_{o} E_{E B a t}}{E_{\text {load }}}$

Table 3

Working parameters and time limits for the experiments.

\begin{tabular}{|c|c|c|c|c|}
\hline \multirow[t]{2}{*}{ Appliances } & \multicolumn{3}{|l|}{ Timing } & \multirow[t]{2}{*}{ Parameters } \\
\hline & $\begin{array}{l}\text { User } \\
\text { (week) }\end{array}$ & $\begin{array}{l}\text { User } \\
\text { (weekend) }\end{array}$ & $\begin{array}{l}\text { Control system (time } \\
\text { interval) }\end{array}$ & \\
\hline $\begin{array}{l}\text { Washing } \\
\text { machine }\end{array}$ & $19: 30$ & $12: 00$ & $07: 00-22: 00$ & $\begin{array}{l}60^{\circ} \mathrm{C} \\
1200 \mathrm{rpm}\end{array}$ \\
\hline Dryer & $20: 30$ & $13: 00$ & $10: 00-24: 00$ & $1200 \mathrm{rpm}$ \\
\hline Dishwasher & $21: 30$ & $20: 30$ & $07: 00-22: 00$ & Quick wash \\
\hline
\end{tabular}

where $\xi \in[0,1]$ defines the amount of energy used by the house that comes from its PV system. When $\xi=1$ all consumption is supplied by the PV system as in an isolated installation. On the other

Table 4

Experiments results - energy parameters during the day.

\begin{tabular}{cllll}
\hline PV shape & Parameter & Control system & User (week) & User (weekend) \\
\hline Profile 1 & $\xi$ & 0.735 & 0.517 & 0.687 \\
& $\eta$ & 1.465 & 1.466 & 1.465 \\
Profile 2 & $\xi$ & 0.770 & 0.641 & 0.769 \\
& $\eta$ & 3.924 & 3.924 & 3.924 \\
Profile 3 & $\xi$ & 0.693 & 0.519 & 0.690 \\
& $\eta$ & 2.066 & 2.066 & 2.065 \\
Profile 4 & $\xi$ & 0.560 & 0.449 & 0.553 \\
& $\eta$ & 0.561 & 0.559 & 0.554
\end{tabular}

Table 5

Experiments results - initial tasks time.

\begin{tabular}{llll}
\hline \multirow{2}{*}{ Setups } & \multicolumn{2}{l}{ Appliances } & \\
\cline { 2 - 4 } & Washing machine & Dryer & Dishwasher \\
\hline User & & & \\
Week & $19: 30$ & $20: 30$ & $21: 30$ \\
Weekend & $12: 00$ & $13: 00$ & $20: 30$ \\
Control system & & & \\
Profile 1 & $10: 50$ & $12: 22$ & $11: 48$ \\
Profile 2 & $13: 00$ & $14: 00$ & $14: 30$ \\
Profile 3 & $15: 34$ & $16: 32$ & $15: 00$ \\
Profile 4 & $11: 40$ & $12: 38$ & $13: 12$ \\
\hline
\end{tabular}

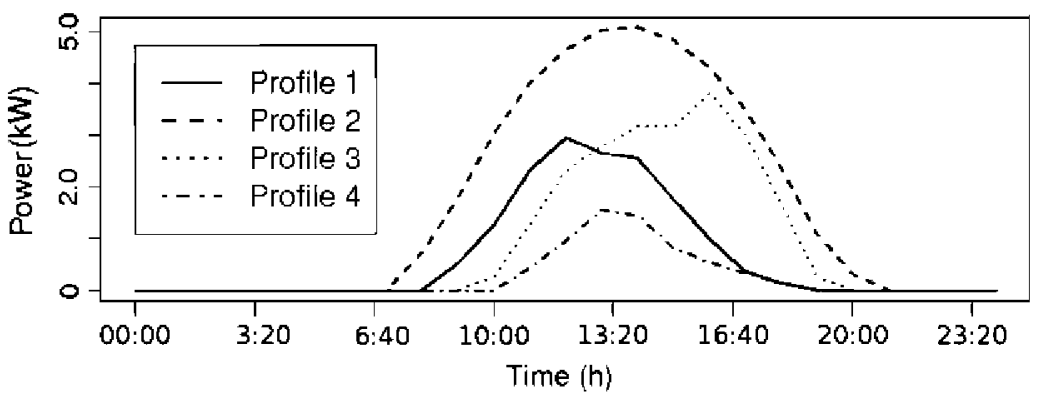

Fig. 7. Forecasted daily PV generation. 


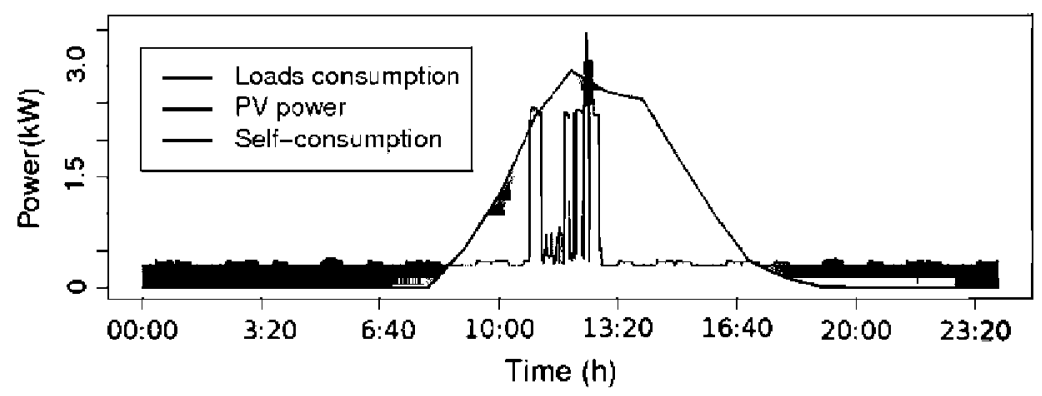

(a)

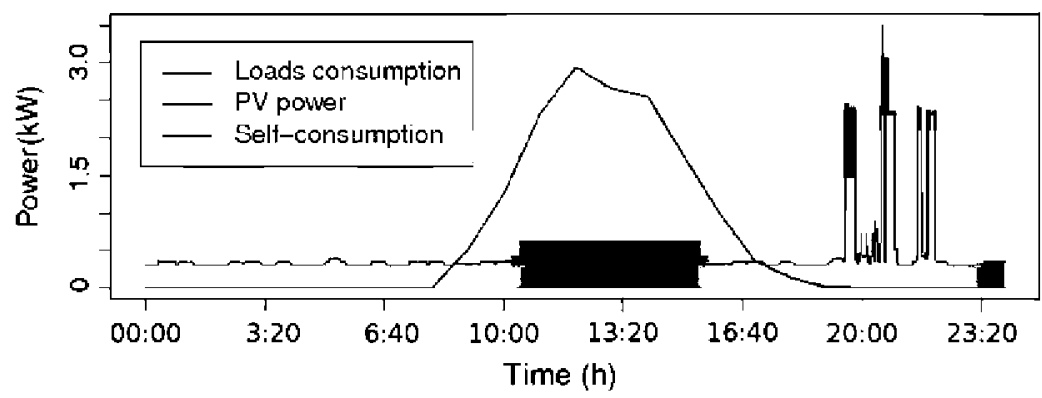

(b)

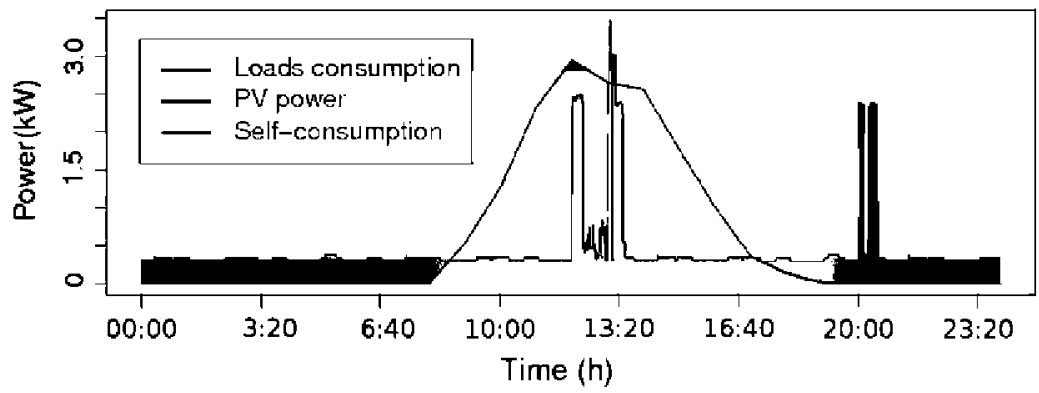

(c)

Fig. 8. Power generation and consumption prediction with Profile 1 for the (a) control system, (b) user (week) and (c) user (weekend).

hand, when $\xi=0$ all the energy is supplied by the grid, as in a conventional house.

Let us define the generated energy as:

$E_{G}=E_{P V}+E_{B s o c, 0}$

As observed in Eq. 9, we consider the generated energy as the one supplied by the PV system together with the initial battery state of charge. This is because in our system all the energy in the batteries comes from the PV system and $E_{B s o c, 0}$ is the excess of energy from previous evaluation periods. Therefore, the battery is also considered as an energy generator in our experiments.

Moreover, the lost energy is:

$E_{\text {lost }}=\left(1-\rho_{i}\right) E_{P V b}+\left(1-\rho_{0}\right) E_{\text {Ebat }}$

As shown in Eq. 10, $E_{\text {lost }}$ considers both the energy inserted and extracted from the batteries with their adequate input and output performance coefficients respectively.

Finally, let us define $\eta$ as the energy coefficient which represents the amount of utile generated energy with regard to the consumed one:

$\eta=\frac{E_{G}-E_{\text {lost }}}{E_{\text {load }}}$

Note that $\eta \in[0, \infty]$, where $\eta=0$ if no energy is generated or all the energy is lost and $\eta=\infty$ when no energy is consumed. On the other hand $\eta=1$ when the generated and consumed energy are the same. ${ }^{1}$

\subsection{Experimental results}

As aforementioned, the EDSM system objective is to schedule different household tasks during the day to improve the energy behavior with regard to a standard user behavior. However, the behavior of a user depends on different factors such as the ownership level, the socio-economic group or the environmental awareness [5]. For the experiments carried out in this paper, we have considered a young worker who is not at home during the daytime at weekdays. Therefore, he does the household tasks at evenings. Nevertheless, in order to consider other setups, we have included a standard weekend day for this user in the experiment. Finally, we compare the energy behavior of the house for both setups (week and weekend days for the user) with the outcome of the EDSM system with small time restrictions.

We have defined the tasks to be carried out by the user as the three primary deferrable loads: (i) washing machine, (ii) dryer and (iii) dishwasher. The time at which the loads must be executed depends on the different setups. As shown in Table 3, the user

\footnotetext{
${ }^{1}$ Note that the battery performance coefficients are included in the equation.
} 


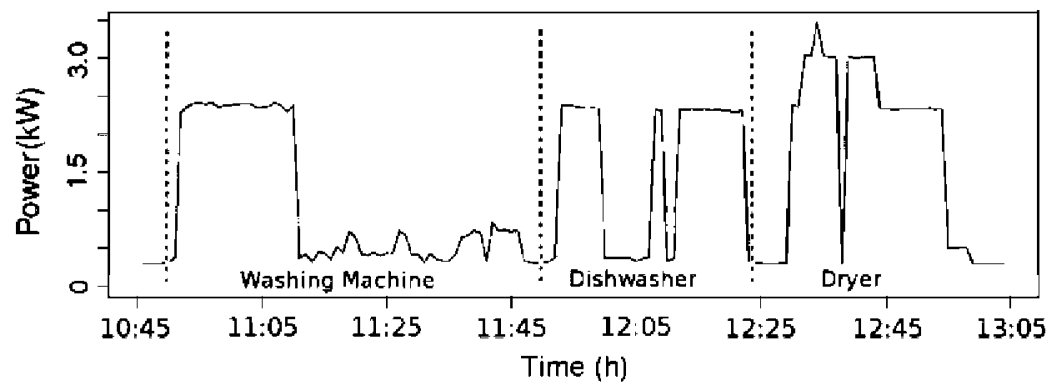

(a)

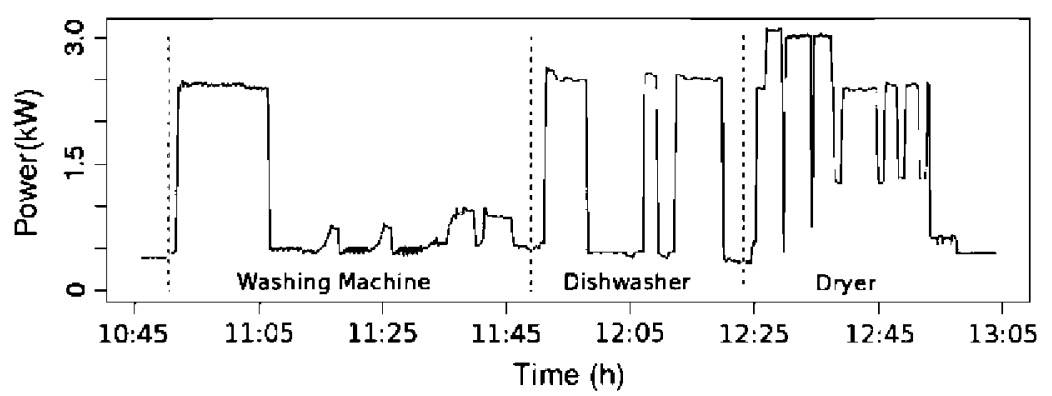

(b)

Fig. 9. Energy consumption: (a) forecasted consumption and (b) real consumption.

behavior is fixed according to his time availability; the tasks must be executed at the evening during the weekday and preferably during the afternoon at weekends. On the other hand, the time interval for the EDSM control system covers all day. Note that in this last setup we suppose that the user has not time restrictions and the appliances are always ready for their execution. Finally, the battery storage capacity has been limited to $2.4 \mathrm{kWh}$. This capacity is more realistic for a real house than the $72 \mathrm{kWh}$ installed in our laboratory house (see Section 2). Moreover, we assume zero initial conditions at the beginning of the experiments, that is $E_{B s o c, 0}=0$.

For the evaluation, we run the experiments in simulation where the information is given to the system and we observe the outcome of the process. In the user set of experiments the system executes the tasks at the time ordered by the user. In the EDSM system experiments, the time intervals are offered to the system. As described in Section 3, the EDSM system creates a planning for each sub-system (i.e., three plannings in our experiments). These plannings are sent to the coordinator which foresees the energy consumption of each planning. Remember that the coordinator makes an estimation based on the forecasted PV generation, the battery state of charge, the appliances consumption and the grid status.

We tested four different PV generation prediction profiles (see Fig. 7) to study the EDSM system behavior. The EDSM system should adapt the tasks' execution to them. Remember, the EDSM system must maximize the self-consumption coefficient $(\xi)$.

Results show that the EDSM system is able to find a better planning than the predefined executions of the user in all experiments. As shown in Table 4, the plannings obtained by the EDSM system improve the self-consumption behavior. The EDSM system obtains the highest $\xi$ for all profiles. Notice that, the energy coefficient $(\eta)$ is similar for all plannings in the same profile. That is because $\eta$ depends on the total PV energy generated. The small changes observed between the plannings, for the same profile, are because of the use of the battery. A planning which uses the battery more frequently obtains a lower energy coefficients because of the battery performance.
Moreover, Table 5 shows a comparison between the time execution proposed by the user and the time at which the EDSM system has decided to execute the tasks. This information could be provided to the user in order to inform about self-consumption improvements. Moreover, this information allows a user without controllable appliances to manually execute the appliances at optimal times. Finally, Fig. 8 shows a graphical comparison of the task scheduling for Profile 1. Notice that a basic consumption level is observed for the experiment duration. This is because the refrigerator, fridge, computer and other loads are always active in the house.

In order to make sure the EDSM system fits the real world, we executed all the plannings at hand in the real house. During execution, the installed electricity meters measured the real consumption in order to monitor the energy flows and to test the prediction accuracy. Notice that the real energy balance depends on different factors which are not controllable by the EDSM system. The most important is the PV energy generation. For this reason, it is unavoidable to find differences between the simulated predictions and the real experiments. However, because we run the real experiments in the immediate days following the simulation experiments, the generated PV energy was similar to the one predicted. Therefore, the self-consumption and energy coefficients were similar too (differences of less than $8 \%$ were observed). Fig. 9 shows a comparison between the execution obtained in simulation and reality by the EDSM system with Profile 1.

\section{Conclusions}

We have presented experimental results of an EDSM system with PV generation as a DER. The combination of EDSM and PV generation allows the use of local control techniques and achieves energy efficient levels. As observed in this paper, these techniques are severely connected with self-consumption. Self-consumption is the most distributed energy implementation, because consumption is at the same place as generation. This electrical topology reduces the transport losses and the energy demand to the grid. 
An EDSM with PV generation could have different energy criterions and operation policies. The experiments presented in this paper follow the criterion of "maximizing the PV energy consumption ". By using this criterion, we obtained that the PV energy used locally increases with regard to the PV energy delivered to the grid. With this operation policy, the load of the grid gets reduced. Moreover, the system allows a reduction on the power peaks demanded and the generation randomness typically present in renewable energy systems.

The evaluation of an installation equipped with generation, storage and consumption is not trivial. In order to study the energy behavior of our system, we have developed two different coefficients: (i) self-consumption coefficient ( $\xi$ ) and (ii) energy coefficient $(\eta)$. The former relies on the self-consumption goodness, while the latter evaluates the installation sizing.

The experiments carried out show that the EDSM system reduces the consumption from the grid. This improvement is observed as a reduction of $1.2-2.2 \mathrm{kWh}$ during the days of the week, for the experiments presented. This is because the principal consumption peaks of the residential sector are found at evenings during the week $[3,6]$. This demand reduction causes not only energy savings but reactions on the grid overloads. On the other hand, the energy coefficient informs about the goodness of the installation with regard to the user loads and PV generation.

\section{Acknowledgments}

This work was supported by the Gestión de la Demanda Eléctrica Doméstica con Energía Solar Fotovoltaica project, funded by the Plan Nacional de I+D+i 2007-2010 (ENE2007-66135) of the Spanish Ministerio de Educación y Ciencia. M. Castillo-Cagigal is sponsored by the Spanish Ministry of Education with a Ph.D. Grant (FPU2009).

\section{References}

[1] Kamal W. Improving energy efficiency - the cost-effective way to mitigate global warming. Energy Convers Manage 1997;38(1):39-59.
[2] Lior N. Energy resources and use: the present situation and possible paths to the future. Energy 2007;33(6):842-57.

[3] Indel P, editor. Atlas de la Demanda Eléctrica Española. Madrid, Spain: Red eléctrica de España; 1998.

[4] Bertoldi P, Atanasiu B. Electricity consumption and efficiency trends in the enlarged European Union. Tech. Rep. EUR 22753 EN, Institute for Environment and Sustainability; 2007.

[5] Mansouri I, Newborough M, Probert D. Energy consumption in UK households: impact of domestic electrical appliances. Appl Energy 1996;54(3):211-85.

[6] Hamidi V, Li F, Robinson F. Demand response in the UK's domestic sector. Electr Power Syst Res 2009;79(12):1722-6.

[7] CEC. Green paper, towards a EU strategy for security of energy supply. Tech. Rep. COM (2000) 769, CEC; 2000.

[8] Papagiannis G, Dagoumas A, Lettas N, Dokopoulos P. Economic and environmental impacts from the implementation of an intelligence demand side management system at the european level. Energy Policy 2008;36(1): $163-80$.

[9] Caamaño-Martín E, Laupkamp H, Jantsch M, Erge T, Thornycroft J, Moor HD, et al. Interaction between photovoltaic distributed generation and electricity networks. Prog Photovoltaics 2008;16(7):629-43

[10] Eltawil MA, Zhao Z. Grid connected photovoltaic power systems: technical and potential problems - a review. Renew Sustain Energy Rev 2010;14(1): 112-29.

[11] Groppi F. Grid connected photovoltaic power systems: power value and capacity value of PV systems. Tech. Rep. IEA PVPS T5-11: 2002, CESI, Milan, Italy; 2002.

[12] Podewils C. Switching can pay off. Photon Int 2008;2008(12):30-7.

[13] Caamaño-Martín E, Novo S, Egido M, Masa D. Demand side management in PV-powered homes: a supervision and decision making tool. In: Proceedings of the 22th European photovoltaic solar energy conference and exhibition. Munich, Germany: WIP-Renewable Energies; 2007. p. 2478-83.

[14] Gutiêrrez A, Jiménez-Leube J, Magdalena L. A distributed sensor network for the control of a bioclimatic house in spain. Sensors 2009;9(10):8197-214.

[15] Duke R, Williams R, Payne A. Accelerating residential PV expansion: demand analysis for competitive electricity markets. Energy Policy 2005;33(15): 1912-29.

[16] Aditya S, Das D. Battery energy storage for load frequency control of an interconnected power system. Electr Power Syst Res 2001;58(3): 179-85.

[17] Wagner R. Large lead/acid batteries for frequency regulation, load levelling and solar power application. J Power Sources 1997;67(1-2):163-72.

[18] Wagner R, Schroeder M, StephanBlome T, Handschin E. A multifunctional energy-storage system with high-power lead-acid batteries. J Power Sources $1999 ; 78(1-2): 156-63$

[19] Kolokotsa D, Kalaitzakis K, Antonidakis E, Stavrakakis G. Interconnecting smart card system with PLC controller in a local operating network to form a distributed energy management and control system for buildings. Energy Convers Manage 2002;43(1):119-34. 